\title{
Orientar e ser orientado: o professor vira orientador
}

\section{To orient and be oriented:}

the teacher becomes an advisor

\author{
Orientar y ser orientado: \\ el profesor se convierte en orientador
}

\section{MARLI TERESINHA SILVA DA SILVEIRA*}

Universidade de Passo Fundo, Passo Fundo- RS, Brasil.

TANIA MARA ZANCANARO PIECZKOWSKI** Universidade Comunitária Regional de Chapecó, Chapecó-SC, Brasil.

ANDREIA HENN GHISLENI ${ }^{* * *}$

Universidade de Santa Cruz do Sul, Santa Cruz do Sul- RS, Brasil.

PAULA LEMOS DA SILVEIRA ${ }^{* * * *}$

Universidade de Santa Cruz do Sul, Santa Cruz do Sul- RS, Brasil.

VANEZA SILVA DA ROSA*****

Universidade de Santa Cruz do Sul, Santa Cruz do Sul- RS, Brasil.

* $\quad$ Mestre em Filosofia pela Universidade Federal de Santa Maria. Atualmente é Doutoranda em Educação na Universidade de Passo Fundo. É poeta, escritora e ensaísta, com dezenas de livros, artigos e contos publicados. E-mail: <marli19silveira@gmail.com>.

* Doutora em Educação pela Universidade Federal de Santa Maria. Professora, pesquisadora e, atualmente, coordenadora do Programa de Pós-Graduação Stricto Sensu (mestrado) em Educação da Universidade Comunitária Regional de Chapecó. E-mail: <taniazp@unochapeco.edu.br>.

*** Graduada em Letras e mestre em Educação pela Universidade de Santa Cruz do Sul. Atua como professora de Ensino Fundamental e supervisora escolar no município de Boqueirão do Leão/RS. E-mail: <andreiaghisleni@gmail.com>.

**** Mestre e doutoranda em Educação pela Universidade de Santa Cruz do Sul. Atualmente é professora na Universidade da Região da Campanha. E-mail: <paulalsilveira@gmail.com>.

***** Mestre e doutoranda em Educação pela Universidade de Santa Cruz do Sul. Atualmente é professora da rede municipal de ensino de Santa Cruz do Sul, atuando no trabalho pedagógico com alunos com o transtorno do espectro autista. E-mail: <vanezasilvarosa@bol.com.br>. 
RESUMO:O objetivo deste artigo é refletir sobre as orientações e sua implicação no processo de leitura e escrita, problematizando aspectos que reverberam na tessitura final de dissertações e teses. Dialoga com as referências teóricas e as narrativas de professores/orientadores interpelados pela questão e implicados pelo ser/tornar-se orientador (a). Considerando-se que inexiste preparo ou um curso específico que habilite um professor a se tornar um professor/orientador, o desafio levará o professor a compreender que exercerá um novo papel, marcado por uma relação de proximidade intelectual que poderá ser exitosa ou não, para ambos os lados.

Palavras-chave: Educação. Escrita. Orientação. Leitura.

ABSTRACT: The aim of this article is to reflect on the orientations and their implication in the reading and writing process, problematizing aspects that reverberate in the final fabric of dissertations and theses. It dialogues with the theoretical references and narrative of teachers / counselors summoned by the question and implied by the being/ becoming an advisor. Considering the nonexistence of a preparation or a specific course that enables a teacher to become a teacher/advisor, the challenge will lead the teacher to understand that he/she will play a new role, marked by a relationship of intelectual proximity that may or may not be successful, for both sides.

Keywords: Education. Writing. Guidance. Reading.

RESUMEN: El objetivo de este artículo es reflexionar sobre la orientación académica y su implicación en el proceso de lectura y escritura, problematizando aspectos que repercuten en el tejido final de disertaciones y tesis. El artículo dialoga con las referencias teóricas y las narrativas de profesores/orientadores interpelados por esa cuestión e implicados por el ser/tornarse orientador (a). Considerando que no hay preparación o un curso específico que permita a un profesor tornarse um profesor/orientador, el desafío hará que el profesor comprenda que desempeñará um nuevo papel, marcado por una relación de proximidad intelectual que puede o no ser exitosa para ambos lados.

Palabras clave: Educación. Escritura; Orientación. Lectura. 


\section{Introdução}

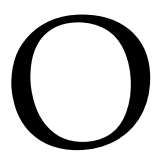

presente texto discute e aponta questões e aspectos relevantes, ainda pouco tematizados, no exercício da orientação em teses, dissertações ou até mesmo conclusão de curso, apontando ser um tema extremamente importante tendo em vista problematizar como o professor se torna orientador, no ensino superior, sendo que inexiste um curso que o prepare e ou habilite a se tornar um professor/orientador. Parte-se do pressuposto de que quem um dia foi orientando, orientador será. Geralmente, os professores que orientam em programas são doutores que já passaram pela experiência da pesquisa.

Embora nem sempre verbalizada, há uma ideia corrente de que a prática ensina e o tempo será o veículo capaz de tornar um doutor um bom orientador. Além da prática ter sido a principal "faculdade" de formação de uma ação didático-orientadora, outras dificuldades são apontadas como impedidoras de uma qualificada relação orientando-orientador, sendo que a dificuldade de acesso ao professor orientador e o seu despreparo para a tarefa da orientação destacam-se como empecilhos a um resultado satisfatório ao final do mestrado ou doutorado. Não menos importantes, pode-se citar que alguns orientandos chegam aos cursos stricto sensu com baixíssima produção escrita, sem desconsiderar a guinada da produção científica brasileira que, desde o final da década de 1990, deixou de focar a formação de professores, para a formação de professor pesquisador no ensino superior.

Mais do que apresentar respostas, este artigo deseja problematizar algumas situações da prática da orientação stricto sensu, de modo especial, interpondo possíveis desdobramentos e diálogos com professores orientadores da Universidade de Santa Cruz do Sul (Unisc) e da Universidade do Vale do Rio dos Sinos (Unisinos), procurando articular experiência, tempo e interlocuções.

Os sujeitos das pesquisas são professores que atuam na docência e orientação em cursos de pós-graduação na Unisc e na Unisinos (RS), reunidos pela experiência/tempo de docência-orientação, ${ }^{1}$ e foram convidados a responder a seguinte pergunta, com base em suas práticas e experiências docentes: Como me torno um orientador(a)? Sabendo-se que talvez nenhum(a) professor(a) se "torne" um orientador(a), mas paute-se pela busca constante pela qualificação da sua relação/formação de colaborador fundamental de pesquisas e interesses dos seus alunos/orientandos.

Articulam-se, a partir das narrativas dos professores/orientadores e com base no referencial teórico, aspectos relevantes para se problematizar como um professor(a) pode se tornar um orientador(a).

Os docentes/orientadores aparecerão indicados por letras, tendo em vista preservarmos sua identidade, e as referências estão contempladas no quadro abaixo, conforme: 
Figura 1 - Narrativas docentes dos professores orientadores

\begin{tabular}{|c|c|c|c|}
\hline Identificação & $\begin{array}{c}\text { Docência } \\
\text { Universitária }\end{array}$ & $\begin{array}{l}\text { Orientação Pós- } \\
\text { Gradução }\end{array}$ & Formação \\
\hline docente "A" & 42 anos & 33 anos & $\begin{array}{l}\text { pedagogia, mestrado } \\
\text { em fundamentos } \\
\text { sociais da educação } \\
\text { e doutorado em } \\
\text { fundamentos da } \\
\text { educação }\end{array}$ \\
\hline docente "B" & 26 anos & 10 anos & $\begin{array}{l}\text { artes plásticas, } \\
\text { mestrado e doutorado } \\
\text { em educação }\end{array}$ \\
\hline docente "C" & 12 anos & 4 anos & $\begin{array}{l}\text { geografia, mestre e } \\
\text { doutor em educação }\end{array}$ \\
\hline
\end{tabular}

Fonte: Própria

O objetivo não é apresentar uma receita de como se tornar/formar um professor/ orientador, mas apontar dificuldades, demandas e sugerir aportes indispensáveis para qualificação da relação orientador/orientando, muitos dos quais presentes nas leituras trazidas para o contexto desta discussão.

\section{Como se tornar um professor orientador}

Ingressar na pós-graduação, seja em nível de mestrado ou doutorado, é, sem dúvida, um desafio. Depois de passar anos frequentando o ensino fundamental, médio e a graduação, grande parte de pós-graduandos encontra dificuldades para expressar ideias e escrever dissertações e teses. Na verdade, não se aprende a exercitar a pesquisa, nem a escrita durante todos esses anos em sala de aula, sendo que, na pós-graduação, precisar-se-á dar conta de tudo, num tempo breve e com a melhor qualidade possível. Bianchetti e Machado afirmam que, para o pós-graduando

[...] a passagem de uma situação de gregarismo na graduação para o enfrentamento de um trabalho praticamente solitário - em que ele é obrigado a responsabilizar-se pela produção do seu próprio texto - é uma mudança muito brusca para ser assimilada em pouco tempo (BIANCHETTI E MACHADO, 2012:184).

Para amenizar as tensões de um pesquisador iniciante, que se defronta com as dificuldades de escrita e a insegurança em relação ao que e como pesquisar, eis que entra em cena o orientador. Ele auxilia na organização e na condução da pesquisa, inclusive ampliando sua função ao amparar os orientandos, em alguns momentos, até mesmo na condução da própria vida. De repente, aquele sujeito que era apenas um professor, 
torna-se um bom amigo, um ouvinte, conselheiro, que, às vezes, precisa dar até mesmo um "puxão de orelha". Muitos terão, por experiência própria, seja durante o mestrado ou doutorado, vivenciado momentos tensos e difíceis, pois, humanos que somos, não conseguimos ter vidas distintas, separando a vida acadêmica de nossa vida pessoal. Acredita-se que essa compreensão, por parte do orientador, é de fundamental importância. Se não houver esse olhar sensível de quem orienta, talvez muitos acabassem até mesmo desistindo da pós-graduação.

O papel do orientador tem relevância não somente pela complexidade da função, em seus diversos aspectos, mas também pela tamanha responsabilidade de capacitar e qualificar alguém a ser autor de seu próprio trabalho. Um dos maiores problemas enfrentados pelos orientadores e orientandos na contemporaneidade, além da dificuldade de escrita e dos inevitáveis conflitos pessoais, é a diminuição de prazos para a escrita das dissertações e teses.

Discutir o papel do orientador, também devido à exigência de produção de artigos e participação em eventos científicos com produção e várias formas de publicações exigidos nos meios acadêmicos, torna-se cada vez mais oportuno. O orientando tem como incumbência a escrita e a reescrita; em contrapartida, o orientador faz sua análise avaliativa, apontando partes dos textos/pesquisa que não estão adequadas e necessitam da reescrita. A tarefa de orientação é individualizada (avaliação da Capes) e a qualificação dos cursos reflete a soma do desempenho dos seus orientadores (CAPES, 1996, p. 18). A experiência acumulada, seguindo critérios de como se avalia o desempenho científico de um pesquisador, baseada na análise de suas linhas de pesquisa, de sua produção científica, número e qualidade dos trabalhos publicados, é um aspecto a ser considerado na orientação. $\mathrm{O}$ frenesi produtivo tem provocado um fenômeno diverso daquele a que se postulava, que é uma qualificada formação acadêmica, pois tem inibido produções mais detidas e jogado os pesquisadores em uma trincheira de competitividade.

Atualmente, com o auxílio de bases de dados, pode-se observar os trabalhos publicados e acompanhar a produção científica dos orientadores. Dessa forma, a escrita, que deveria ser algo prazeroso e agradável, passa a ser encarada como uma imposição rigorosa pela Capes e CNPQ, indo contra o processo educacional, que demanda tempo para um trabalho de qualidade. Bianchetti, citando Warde (2012), afirma que

\footnotetext{
Se trata de um problema de difícil solução, posto que o ritmo e a qualidade da escrita dos nossos orientandos são regidos por relógios psicológicos, biológicos e financeiros não ajustados aos cronogramas do orientador, do programa e das bolsas" (BIANCHETTI apud WARD, 2012:192).
}

Nesse sentido, em meio aos desafios encontrados, é interessante problematizar de que forma o pós-graduando torna-se orientador. Parece ser automático que, no momento em que o pesquisador defende sua tese, e tornando-se doutor, é considerado apto a ser orientador. Orientar, equivocadamente, parece uma tarefa simples, que não exige 
qualificação complementar. Conforme Bianchetti e Machado, "num passe de mágica o orientando se transforma em orientador. O abracadabra é a defesa da tese" (BIANCHETTI; MACHADO, 2012, p. 184).

Em que momento um professor que passou pela pós-graduação (agora doutor) se torna um orientador? O título de doutor (ou mestre), a experiência acumulada ou o número de orientações seriam indicativos de uma espécie de capacitação intelectual para a orientação?

Por mais qualificadas que sejam as experiências na vida docente de um professor, por mais destacados sua formação e anos de atuação, não repercutem sozinhos para a garantia de uma satisfatória orientação. Em muitos casos, quem sabe na grande maioria, o processo vai se desenhando a partir das escolhas, como nos apresenta a docente " $\mathrm{A}$ "2 que destaca que apesar de tantas experiências significativas na sua vida docente, nunca conseguiu saber de fato o que significa ser "orientadora" de trabalhos, de pesquisa, de dissertação, de tese. Iniciou-se como orientadora, lembra, quando, já atuando na graduação (UFRGS), teve um projeto aprovado com direito a bolsista de iniciação científica. "Ali, de repente, começava minha história como orientadora. Lembro que a bolsista que selecionei (inteligente, dinâmica, estudiosa) já tinha participado de pesquisa e isso foi ótimo, pois aprendi muito com ela. Até hoje somos amigas".

A docente " $\mathrm{A}$ " ressalta que, talvez inconscientemente, seguiu o bordão "é caminhando que se aprende a caminhar". Avalia que foi tateando, experimentando modos de ser orientadora:

O que sempre me favoreceu foi a paixão pelo que fiz e faço. Entendi de princípio que o papel de orientadora não deveria ser muito diferente do de professora e talvez por isso não me foi difícil. Nem sempre pude selecionar o aluno ou aluna que orientaria. Mas, felizmente, tive raríssimos "casos difíceis". Desde logo percebi que precisava conhecer mais a fundo a aluna ou aluno que orientaria. Por isso, os primeiros encontros sempre foram informais, de conversas e tentativas de mútuo conhecimento. Sim, também sempre considerei fundamental me fazer conhecer. Ou seja, que tipo de pessoa, professora e orientadora tenho sido, meus valores, posicionamentos políticos e epistemológicos, quais meus propósitos em educação, minhas escolhas de pesquisa, etc. (Docente "A", 2016).

A tarefa de orientar é complexa e, muitas vezes, a experiência de vida pode influenciar no tipo de orientador que teremos. Muitas situações vivenciadas pelo orientador podem refletir na forma como conduzirá o trabalho de seus orientandos e, por conta disso, a relação pode ser menos ou mais qualificada do ponto de vista dos objetivos propostos: TCCs, dissertações, teses.

A relação vertical, percebida entre os docentes e seus alunos, normalmente na pós-graduação, é substituída por uma relação mais pessoal, de trabalho compartilhado com diálogo e amizade, embora não menos profissional. Ao ingressar no mestrado, a maioria não tem maturidade teórica suficiente para conduzir, sozinha, a caminhada de 
pesquisador. Assim, como orientandos, considera-se o papel do orientador de extrema importância para dar suporte e segurança, principalmente nos momentos em que os orientandos se sentem um tanto perdidos em relação ao que, de fato, querem pesquisar.

E aqui mais uma vez citamos a experiência da docente " $\mathrm{A}$ ", para quem desde os primeiros encontros de orientação, em conjunto, orientadora-orientando/a fazem combinações. Com o tempo se aprende que, nas primeiras semanas, já se pode perceber o "modus operandi" a utilizar com cada orientando/a, ou seja, "alguns produzem melhor sob pressão e outros só funcionam se não forem pressionados. E entre estes dois extremos estão todos os demais com suas idiossincrasias" (Docente "A", 2016). Orientar exige sensibilidade do orientador, que aos poucos vai percebendo jeitos e formas adequadas de orientar cada um(a) dos seus orientados (as) e estabelecendo uma relação mais horizontal e menos apreensiva, de parte a parte (Docente " $A$ ", 2016).

O orientador poderá auxiliar e potencializar as pesquisas ou, em alguns casos, permitir que se tornem apenas mais uma produção de pouca qualidade. Assim, a qualificação de quem orienta também é muito importante, pois os orientandos necessitam e muito desse amparo e olhar atento aos trabalhos/projetos desenvolvidos. A docente " $\mathrm{A}$ " destaca que

Uma das dificuldades maiores que encontrei como orientadora foi o fato de ter que lidar com temas os quais eu não tinha aprofundamento. Isso ocorre muito em instituição privada, ocasionando uma demanda grande de estudos por parte de quem deve orientar. A mim especialmente este se tornava um obstáculo maior pois só sei trabalhar com paixão. E às vezes não encontrava dentro de mim nenhum gosto pelo tema de escolha do orientando/a. Em algumas oportunidades consegui fazer um bom casamento entre o que ele/a e eu queríamos (Docente " $\mathrm{A}$ ", 2016).

Haguette (2012) aborda a questão da qualificação teórico-metodológica do orientador como um dos fatores determinantes da qualidade da produção do conhecimento na pós-graduação, uma vez que "o aluno fica à mercê da competência ou incompetência do orientador." (p.162). Nesse aspecto, o professor/orientador precisa reconhecer sua implicação intelectual no processo de orientação, avaliando ou reavaliando sua interlocução interessada com o orientando.

O processo de orientação na área da Educação é didático e o orientador também aprende, se qualifica e amplia seus conhecimentos com a pesquisa de seus orientandos. Para Zilbermann, "dotado de um saber limitado, cada orientador expõe indiretamente humildade suficiente para se curvar à aprendizagem de que igualmente está sendo objeto" (p. 340). Da mesma forma, o orientando vai se tornar orientador ao ampliar sua investigação e, avançando na pesquisa, vai amadurecendo e percebendo como se dá o processo de orientação de produção do conhecimento.

O processo interpessoal de aprendizagem mútua e contínua representado pela relação entre um orientador e cada um de seus orientandos é provavelmente a principal novidade da educação e da ciência brasileira dos últimos trinta anos do século XXI (ZILBERMANN, 2012, p.340). 
Outro aspecto relevante que deve ser considerado na tematização do tema da orientação, do ser-tornar-se orientador(a) é que as expressões “ser professora" e "ser orientadora" na pós-graduação estão colocadas na condição do seu devir como professor (a) e partem da convicção de que não há como pensar e planejar ações educativas cindidas do modo como pensamos, como sonhamos e interrogamos o mundo, do modo como convivemos em linguagem, como oportunamente nos apresenta a docente " $\mathrm{B}$ "3.

Para a docente, o seu diálogo, na pesquisa e na extensão, tem se mostrado em sua abertura ao inesperado e imprevisível que é viver no mundo comum, que a ação educativa diz respeito a um encontro impossível de ser pré-fixado, pré-determinado em respostas tranquilizadoras, mas vai se constituindo em cada texto, em cada escuta da voz do professor e do aluno, em cada ação hermenêutica, em cada ressonância interpretativa, em cada encontro educativo (Docente “B”, 2016).

\footnotetext{
Minha experiência tem me mostrado que o processo de aprender a pensar, seja na criança, no jovem ou no adulto, é sempre um processo delicado e sutil. Assim, a educação universitária - dada em seu catálogo de cursos - não é suficiente. Supõe uma formação que considere a simultaneidade ou temporalidade de suas diferentes dimensões: inicial, continuada, cultural. Significa que a professoralidade, a autonomia docente universitária é constituída com os discentes enquanto ação intelectual, portanto cultural, compartilhada entre pessoas capazes de se auto organizarem em diferentes campos do pensamento (Docente "B" 2016).
}

O encontro com os devires linguageiros, salienta a docente " $\mathrm{B}$ ", encanta não pelo contraste entre as idades, mas pelos encontros com a potência - tão sensível quanto inteligível - com a alteridade ou a diferença temporal nos modos de plasmar experiências de pensamento. "Fui compreendendo, muitas vezes sem entender, que se vive do jeito que se pensa. Pensar sempre tem consequências em nossa existência, seja no plano pessoal, seja no plano político da coletividade." (Docente “B”, 2016). Ressalta que na experiência de pensar e significar a convivência, não há "menoridade" ou "ignorância", não há alguém que sabe "menos" e outro que sabe "mais", ambos sabem de modo diferente.

A aprendizagem maior do movimento de "tornar-me professora-pesquisadora-orientadora", conforme recorda a docente " $\mathrm{B}$ ", foi, antes de tudo, aquela que extraiu da convivência com as crianças pequenas. "Foram elas - e ainda são - que me ajudaram a interrogar certezas, que contribuíram para instaurar contradições e paradoxos na coexistência" (docente "B"). A alteridade linguageira que "instaurou meu desejo intelectual de aproximar fenomenologicamente - ou seja, existencialmente - poesia e filosofia para pensar o que não sabia poder pensar".

A orientação é marcada pelo encontro entre dois sujeitos diferentes, em algumas situações, inclusive, com recortes teóricos distintos. Aprender o que isso significa antecipadamente é abrir-se para a possibilidade de se orientar com vistas ao outro e o que ele também pode ensinar nesse processo- a alteridade falante de um outro que diz e deseja 
ser ouvido e ou que pode auxiliar na construção de uma caminhada parceira, prescindindo de programações estanques, fechadas ou de uma receita pronta, assegurada, muitas vezes, pelo menosprezo de uma das partes.

Castro (2012) ressalta, nesta perspectiva, que cada orientador tem seu estilo pessoal de trabalho. Seguramente, alguns serão melhores ou piores, o que inclusive pode depender do orientando, mas de forma alguma haveria modelos de atuação pessoal que fossem únicos ou necessariamente melhores. Dentre os orientadores, há variedade de personalidades e estilos de trabalho, sendo, portanto, imprescindível a abertura para um trabalho dialógico, compartilhado, até porque também os orientandos têm personalidades e estilos diferenciados.

Com base nisso, o docente " $\mathrm{C}^{\prime 4}$ aponta que ser um professor orientador significa ser um parceiro de escrita, não propriamente por meio da escrita de "um" ou " $\mathrm{do}^{\prime}$ " trabalho dos orientandos, mas a partir do compartilhamento e, no limite, do balizamento de ideias e práticas de pesquisa que possam ser produtivas de acordo com os contextos em que se inserem as pesquisas acadêmicas.

De certo modo, pensando mais poeticamente, para além disto, o professor orientador se torna ainda (nos bons casos), um padrinho, ou seja, alguém que produz junto aos orientandos metas e rotas a serem seguidas no percurso acadêmico (Docente “ $C$ ", 2016).

Para além das ações práticas de orientação - aquelas direcionadas ao desenvolvimento das pesquisas - a função do professor orientador abrange uma espécie de “ambientação" dos orientandos ao mundo acadêmico (Docente “ $C$ ", 2016).

Pensando por este caminho, acredita-se que a leitura e a escrita constituem-se como propostas as mais desafiadoras do que se pode chamar de processo de orientação ou relação orientador/orientando, da escola ao ingresso na universidade, "da escrita no ensino fundamental à tese de doutoramento há uma trajetória permeada de muitas dificuldades" (CHASSOT, 2012, p. 104).

O poeta Mário Osório Marques (1997) nos diz: "escrever é preciso" como um manual para teses e dissertações em que no seu subtítulo descreve: "o princípio da pesquisa". Orientar será, muitas vezes, um ensinar a escrever. Muitas vezes, portanto, o ensinar a escrever se faz necessário.

Para Bianchetti e Machado (2012), "as pessoas têm tendência à procrastinação", que é o ato de adiar o trabalho de escrever, é o difícil momento de passar as ideias para o papel, ou a também denominada "síndrome da folha em branco". Neste sentido, apontam que o tema escolhido e o método são indispensáveis, pois é um trabalho que se faz passo a passo, escrevendo e reescrevendo, até se chegar à versão definitiva. O papel de orientar é muito importante nesse momento, envolvendo muito mais do que acompanhar o aluno, é a garantia de que a produção escrita se desenvolverá de maneira qualificada e com relevância para vir a público. 
Tanto para o orientando como para o orientador, o trabalho parte da escolha do tema e da contextualização do problema, de uma boa introdução, revisão da bibliografia, análise do referencial teórico e do processo de escrita que seja capaz de apresentar argumentos, estabelecer relações e autonomia de formulação e de pesquisa:

Mas, o que é pesquisar? No meu entender é produzir um texto de rica intertextualidade onde se conjuguem, em uma intersubjetividade sempre ativa e provocante desde suas bases socioculturais, as muitas vozes de uma comunidade argumentativa especialmente convocada para o debate em torno de determinada temática; sejam as experiências do pesquisador, sejam os testemunhos de um campo empírico, sejam os testemunhos do respectivo campo teórico (MARQUES, 1997, p. 98-120).

A autoria do pesquisador revela-se como o que assume suas responsabilidades jurídico-institucionais e morais. Nesse sentido, a originalidade consiste em expressar de maneira própria no seu texto o que outros, em outros contextos, disseram.

Deve-se reconhecer, oportunamente, que orientar em uma era em que a velocidade de difusão de informações é desenfreada, o processo é dinâmico e tudo se altera rapidamente, é tarefa árdua e grandiosa. O tempo torna-se cada vez mais raro e precioso para todos nós, e desta forma, a relação entre orientadores e orientandos precisa também fluir para que se produza um trabalho original e a pesquisa obtenha bons resultados.

Embora o presente artigo não tenha como objetivo problematizar a orientação nos diferentes espaços, levando-se em conta a estrutura e as novas mídias, cabe ressaltar que as novas tecnologias têm oferecido possibilidades antes inimaginadas também no campo da orientação stricto sensu, ampliando o acesso aos orientadores e qualificando a discussão entre grupos de pesquisas balizadas por temas e objetos similares. A orientação real/ pessoal, com a presença do orientador e orientando é, sem sombra de dúvida, uma das mais importantes, embora, nos dias atuais, devido ao grande número de recursos e aparatos tecnológicos, torna-se possível também a orientação virtual através dos editores de textos, skype, e-mails e compartilhamentos.

É indiscutível a orientação real presencial (CHASSOT, 2012), aquela dita olho no olho, mas nos dias atuais o uso da tecnologia nos proporciona orientação virtual através da internet como uma alternativa válida quando das usuais dificuldades para encontros reais.

A discussão de situações envolvendo a orientação internética na elaboração de dissertações e teses, em que mostra as possibilidades de uma orientação virtual, inclusive através de descrição de situações experienciais, vale privilegiar a modificação exponencial e os processos de escrita vivida em tempos recentes, em que há aqueles que se alfabetizam em uma lousa e que hoje escrevem com computadores (CHASSOT, 2012: 112).

Nas orientações virtuais, a real distância entre orientador e orientando se mede pela facilidade de um outro acessar a internet, e essa é uma marca dos novos tempos, em que estar fora da rede é uma limitação profissional. Primeiramente, eram trocados disquetes 
pelo correio, depois por conta de e-mail com anexo em que se faziam anotações, correções e comentários (CHASSOT, 2012).

Hoje, com a evolução, sofisticação dos editores de textos e novidades na internet, convive-se com instrumentos que revolucionaram o processo de escrita cada vez mais colaborativos e facilitadores dos nossos afazeres, permitindo o uso de marcadores de comentários e anotações enviados por e-mail ou em tempo real compartilhado. Pode-se, na atualidade, utilizar grupos de discussão online, para orientação, com diferentes orientandos, envolvidos em temas de pesquisa semelhantes, um ajudando o outro em suas dúvidas (CHASSOT, 2012).

O lugar da prática educativa também surge como aspecto a ser considerado, pois pensar a formação docente na interlocução com a orientação é também questionar algumas afirmações que posicionam os docentes em determinados lugares na prática educativa. Neste aspecto, poder-se-ia perguntar qual significado tem a afirmação de "não estar preparado" para ser orientador.

Em um contexto político-econômico, a formação se coloca como constante, sendo o professor um consumidor ativo. Se, em um construto social, a profissão docente caracterizou-se por missão, sacerdócio, vocação, amor, na atualidade estas marcas não se anularam; no entanto, o professor constitui-se, hoje, muito mais como um gerenciador de sua formação, um empreendedor, cuja formação é inacabada. Também se refere, nessa preparação, o sentido das relações pessoais e afetivas que envolvem a incumbência de ser um professor orientador. Ao mencionar o saber, faz-se significativo considerar as contribuições de Tardif (2012) acerca dos saberes docentes enquanto pluralidades atuantes nesta profissão:

[...] a relação dos docentes com os saberes não se reduz a uma função de transmissão de conhecimentos já constituídos. Sua prática integra diferentes saberes, com os quais o corpo docente mantém diferentes relações. Pode-se definir o saber docente como um saber plural, formado pelo amálgama, mais ou menos coerente, de saberes oriundos da formação profissional e de saberes disciplinares, curriculares e experienciais (TARDIF, 2012, p.36).

A totalidade dos saberes engloba a prática educativa, sendo traduzida no saber da experiência. Experiência que possui sua valoração na formação docente, uma vez que interpela as relações orientador e orientado na pesquisa acadêmica. Como a experiência contribui na constituição/formação do professor orientador? Quais são os saberes que contribuem na relação do orientador com o seu orientando?

A experiência é o que "nos passa, o que nos acontece, o que nos toca. Não o que se passa não o que acontece, ou o que toca". (LARROSA, 2015. p.18). Ao trazer estes argumentos teóricos para a discussão da experiência docente na orientação, percebe-se a vinculação das histórias de vida profissional e pessoal, ou seja, a sua trajetória enquanto aluno, a experiência de ser orientado. Paulatinamente, neste percurso da formação 
docente, a busca por uma pós-graduação cada vez mais é enfatizada, sendo necessário professores orientadores para contemplar esta demanda. Neste processo, os livros também se tornam recursos para a orientação, descrevendo o "receituário" de como elaborar os trabalhos acadêmicos.

Tanto as obras já catalogadas nas bibliotecas quanto as mais recentes, disponíveis nas livrarias, denotam o reconhecimento de que o ato de formular as ideias e expressá-las por escrito é tarefa árdua e requer novas formas de encaminhamento (BIANCHETTI; MACHADO 2012, p.30).

Na relação da orientação com os livros, questiona-se a prescrição dos "modelos" de escrita, procedimentos, roteiro a ser seguido, os quais denotam a funcionalidade de auxiliar na elaboração dos trabalhos acadêmicos, estando próximo ao professor na relação de orientar. Com base nisso, pode-se considerar que os livros colaboram para a formação/qualificação do professor orientador? Ou se intitulam como livros orientadores? Em ambos os questionamentos, os livros não poderão substituir a relação dos orientadores/ orientandos com a pesquisa, todavia poderão contribuir, desde que não se tornem isoladamente materializados na orientação. O orientador é indispensável na relação, inclusive por possibilitar que as leituras sejam qualificadoras da escrita e capazes de assegurar um trabalho original e comprometido com as novas perspectivas das pesquisas em questão. A referência aos autores (BIANCHETTI; MACHADO; 2012, p.31) é pertinente, pois descrevem:

\begin{abstract}
O orientador, diferentemente do livro que orienta, é um personagem que entretém uma relação singular e intersubjetiva com seu orientado, de peculiar riqueza e complexidade, por sinal. O orientador juntamente com o orientado e suas páginas escritas constituem um trio único e original, com considerável espaço de liberdade, voltado para construir conhecimentos, bem como favorável ao desenvolvimento de um estilo pessoal na escrita.
\end{abstract}

Entretanto, a relação orientador/orientando também é movida por um espaço de tensão, em que a convivência efêmera, devido aos curtos prazos para a entrega dos trabalhos e conclusão do curso, dificulta um estudo mais abrangente do objeto de pesquisa. Além disso, há o fato de que tal relação orientador/orientando é influenciada pelos livros e manuais de pesquisa, e que o orientador poderá conduzir o seu orientando a um campo restritamente metodológico, tornando-se um processo fragmentado e desprovido da autonomia criativa e dialógica que contribui imensamente para a pesquisa.

Problematizar o que qualifica e ou quando um professor se torna um orientador é - mesmo que careçamos de certezas se existe ou mesmo se deva existir um momento em que um professor se torna de fato um orientador -,igualmente, questionar os fatores que intervêm nesta pluralidade da formação acadêmica e de pesquisa, processo que não é objeto de estudo em pesquisas e literaturas ou permanece insipiente. A prática tem 
sido o lugar mesmo a partir do qual um professor se habilita como orientador, sem contar a experiência de ter sido um dia um orientando. Por oportuno e considerando que se essas contribuem na qualificação/formação do professor orientador, considera-se que o orientador busca metodologias que aproximaram o orientando dos estudos de autores e se comporte de forma acolhedora; do contrário, haverá fratura e fragmentação na formação dos doutores/orientadores.

Em que momento da vida profissional um professor (doutor) sentiu-se/tornou-se orientador? É imprescindível considerar a importância do professor orientador na formação de pesquisadores, visto que a sua função de orientar poderá qualificar a autoria de ambos. No entanto, para se chegar a esta qualificação há incertezas, limitações, vínculos afetivos, que englobam a relação de orientar, pois ambos são pessoas singulares, com suas particularidades e que objetivam a pesquisa. Há um momento em que um professor (doutor) tenha condições reais, intelectuais e morais para se intitular orientador? A relevância do orientador é indiscutível. Se há ou deve haver um modelo a ser seguido é que é a questão.

\section{Conclusão}

O desafio de ser orientador, considerando que muitos orientandos chegam à pós-graduação sem uma experiência significativa na produção escrita, além das dificuldades próprias das novas relações acadêmicas e demandas específicas, deve levar o professor/ orientador a compreender que exercerá um papel que precisa ser pautado pela necessária disponibilidade para o outro que chega, constituindo uma caminhada parceira e compartilhada. Da mesma forma, reconhecer que não estará "formado" para ser orientador, o que pode, em um primeiro momento, causar angústia, mas, se adequadamente trabalhado, implicar uma reiterada abertura para novas leituras e encontros, colaborando para a construção da autonomia de pensamento e de ação, capacitando os orientandos para novas reflexões, instigando-os no seu papel de futuros pesquisadores.

A tarefa do professor orientador não é neutra, ou seja, no momento em que o professor se intitula como orientador o seu processo de formação docente caminha junto. A sua experiência, os seus saberes, enfim, a sua história de vida pessoal e profissional alicerçam o saber ser orientador.

Em se tratando de uma relação singular, por mais que se repitam as práticas de orientação nas universidades, a falta de um curso ou receita para qualificação de um professor/orientador não é um problema, pelo contrário, uma idiossincrasia fundamental e que pode tornar a relação orientador/orientando um exercício de autonomia e liberdade com vistas à qualificação de pesquisas e conteúdo. Mesmo que a forma seja importante e potencialize a pesquisa e seus resultados, o produzido deve estar na base das orientações, pois serão os conteúdos mobilizadores de perspectivas e marcadores científico-culturais. 
O que está colocado é que o professor/orientador deve ser capaz de acolher o orientando e possuir condições humanas e intelectuais para apontar caminhos, sugestões e permitir, ao abrigo das leituras e respaldos técnico-metodológicos, que a pesquisa se desenvolva com naturalidade e a escrita seja o resultado de um constante fazer, refazendo-se. Como elencado, em relação ao orientador, a falta de qualificação profissional, despreparo e a dificuldade dos orientados em aproximarem-se, terem acesso ao orientador, são obstáculos que tornam desqualificada e tensa a relação orientador/orientando, quando não, levando muitos pós-graduandos a desistir dos seus cursos. Por sua vez, os orientandos chegam, não poucas vezes, desprovidos de condições efetivas de escrever textos seguros e reflexivos, tornando dramática a relação com o orientador e com suas fontes e nortes de pesquisa. Não se pode descartar situações em que os orientandos acabam buscando outros desdobramentos de pesquisas e as dificuldades surgidas com orientandos que também são trabalhadores (não possuem bolsas e apoio para o desenvolvimento de suas pesquisas).

Tornar o processo de ensino-aprendizagem um exercício constante de produção e pesquisa horizontal é uma tarefa imprescindível para a qualificação dos orientandos e futuros orientadores, evitando que pós-graduandos ingressem no ensino superior e à atividade docente sem o mínimo de condições de problematizar temas, contextualizar problemas e alcançar soluções, mesmo que temporais. Tais pré-requisitos já habilitam, em grande medida, professores a se tornarem orientadores. Há que se considerar ainda a importância da relação orientador/orientando, que deve ser potencializada pela acolhida aos diferentes atores envolvidos e pela dinâmica da escrita orientada pelos anseios/ desafios que pautam um projeto de pesquisa.

A docente " $\mathrm{A}$ " conta uma historinha que ilustra muito bem o que tentamos apontar no presente trabalho: "Estava um dia integrando uma banca junto com a colega " $X$ " e fiquei muito feliz quando ela (superexperiente, uma referência na área da educação) falou: não se faz curso pra "ser banca", a gente vai aprendendo a "ser banca". Eu fiquei tão feliz naquela hora porque era justo o que eu sempre pensava. O mesmo acontece com ser orientadora, a gente vai aprendendo a vida inteira a ser orientadora". Não muito diferente, o docente " $\mathrm{C}$ " também diz não saber se já se tornou um orientador, nem mesmo se um dia se tornará, pois os processos de transformação são tão dinâmicos quanto a vida, já que eles são a vida. Segundo ele: "me torno orientador a cada instante, tendo em vista as diferentes situações pelas quais passo junto aos orientandos. Contudo, considerando a necessidade de apontar um ponto de partida, eu diria que aquilo que faço parte de fragmentos de vivências, positivas e negativas, que me oportunizam me colocar na posição de quem desenvolve e escreve uma pesquisa" (Docente "C", 2016). Suas referências são aquelas que o orientaram e orientam.

Merece especial atenção o que nos diz a docente "B": "Como disse Gaston Bachelard (1994, p.46), podemos ensinar os começos - as repetições, nunca as transformações 
- as mudanças - as composições. Pois são instantes - tempos - realizadores, que dependem de espaços e de dimensões de linguagem que favoreçam constituí-los, narrativas que signifiquem o vivido comum. Significa acolher que uma professora, no meu caso, pode indicar ou orientar caminhos ("conteúdos"), mas não pode ensinar a operá-los (a caminhar), ou seja, o que cada um fará com eles! Assim, na experiência de pensar, não há modelos, não há prévios modos de acontecer, não pode ser ensinado porque não pode ser fixado, só pode ser apreendido ou empreendido com os outros no movimento mesmo de pensar. Gosto de meu devir professora porque aprendo com os devires dos outros a pensar o que não sabia poder pensar (Docente “ $\mathrm{B}$ ”, 2016).

O caminho é caminhar, deve ser construído a cada nova orientação, contudo, o orientador deve estar preparado, - estar preparado no que se refere ao ter realizado uma qualificada formação docente, de produção e pesquisa, aberto aos novos desafios e anseios de futuros mestres e doutores - para receber o orientando, disposto a fazer suas leituras e acompanhá-lo no desenvolvimento da pesquisa. Qualificação e sensibilidade são requisitos básicos para uma qualificada orientação. Não se trata de uma receita, mas de uma necessária disposição para o desafio de se produzir algo para o coletivo, em que a autonomia e a perspicácia científico-metodológica foram exercitadas e não tolhidas no processo de orientação. Nesse sentido, se de um lado torna-se indispensável uma boa formação, inclusive complementar e continuada, para "formar-se" um bom orientador também é requisito básico um olhar que acolhe e esteja disposto a conduzir dialogicamente para um resultad o final (dissertação, tese), o que podemos chamar de sensibilidade formadora - a tarefa de orientar e ser orientado.

Recebido: 19/02/2019, Reapresentado: 14/08/2019 e Aceito: 29/08/2019

\section{Notas}

1 As narrativas dos professores-orientadores compõem-se das suas respostas à pergunta formulada: Como me torno um Orientador(a)? Tendo em vista compreender como se dá este processo de formação "pela experiência", não havendo um curso para formar orientadores, os sujeitos da pesquisa foram reunidos pelo tempo/experiência de docência-orientação de dois programas de pós-gradução igualmente diferenciados pela trajetória/tempo de criação dos mesmos.

2 Docente "A": Pedagoga com mestrado em Fundamentos Sociais da Educação e doutorado em Fundamentos da Educação. Iniciou sua atividade docente (profa. anos iniciais) em 1967 e em 1970 no ensino médio. No curso superior sua docência teve início em 1976, na Unisinos, e a partir de 1985 começou sua atuação como orientadora de TCC e iniciação científica (UFRGS) e mestrado e depois doutorado, 2001(Unisinos).

3 Docente "B": Graduada em Educação Artística Habilitação Artes Plásticas, pela Universidade Federal do Rio Grande do Sul, com mestrado e doutorado em Educação, pela Universidade Federal do Rio Grande do Sul. Pesquisadora e professora adjunta do Departamento de Educação, atuando na graduação, na extensão 
e no Programa de Pós-Graduação em Educação da Universidade de Santa Cruz do Sul. Atualmente é coordenadora adjunta do PPGEdu, líder do Grupo de Estudos Poéticos da Unisc e vice-líder do grupo de pesquisa LinCE - Linguagem, Cultura e Educação da Unisc. Tem experiência na área de educação, com ênfase em Educação, Arte e Infância, principalmente nos seguintes temas: aprendizagem, imaginação criadora, experiência poética, artes plásticas, educação infantil e ensino fundamental. Iniciou sua atuação como professora orientadora em 1992, no curso de Pedagogia da Universidade de Santa Cruz do Sul e desde o ano de 2009 orienta no Pós-Educação Unisc.

4 Docente "C": Graduado em Geografia, mestre em Educação, doutor em Educação e possui seu pós-doc em Saúde Coletiva. Começou a trabalhar como professor de Geografia, na educação básica, área da Educação de Surdos, no terceiro semestre da graduação. Após concluída a graduação, ingressou no mestrado em Educação. Partindo disso, criou e coordenou um curso de especialização em Educação de Surdos, na Ulbra, em 2006. Nesta ocasião passou a orientar TCC no curso e em outros pelos quais fora convidado (Unilasalle, Ulbra e Unisc). Já são mais de 45 orientandos de especialização e, após concluir o doutorado, em 2014, foi coorientador de uma dissertação na Ufrgs e, agora, na Unisc.

\section{Referências}

BIANCHETTI, Lucídio, MACHADO, Ana Maria Netto. A bússola de escrever: sobre a função da orientação de teses e dissertações. 3 ed. São Paulo: Cortez, 2012.

CASTRO, Cláudio M. Memórias de um orientador de tese: um autor relê sua obra depois de um quarto de século. In: NUNES, Edson Oliveira de. A aventura sociológica. Rio de Janeiro: Zahar editores, 1978. p.307-326.

CHASSOT, ATTICO I. Orientação Virtual: uma nova realidade. In: BIANCHETTI, Lucídio, MACHADO, Ana Maria Netto. (Orgs). A bússola de escrever: sobre a função da orientação de teses e dissertações. 3 ed. São Paulo: Cortez, 2012.

DIAS, Sônia M. R.C.; PATRUS, Roberto; MAGALHÃES, Yana T. Quem ensina um professor a ser orientador? Proposta de um modelo de orientação de monografias, dissertações e teses. Administração, Ensino e Pesquisa, Rio de Janeiro, v. 12, n. 4. p. 697-721, 2011.

HAGUETTE, Tereza Maria Frota. Universidade: nos bastidores da produção do conhecimento. In: BIANCHETTI, Lucídio, MACHADO, Ana Maria Netto. (Orgs). A bússola de escrever: sobre a função da orientação de teses e dissertações. 3 ed. São Paulo: Cortez, 2012.

LAROSSA, Jorge. Tremores escritos sobre experiência. Belo Horizonte. Autêntica, 2015.

MARQUES, Mario Osorio. Escrever é preciso: o princípio da pesquisa. Ijuí: Editora UNIJUÍ, 1997.

MARQUES, Mario Osorio. A orientação de Pesquisa nos Programas de Pós-Graduação. In:

BIANCHETTI, Lucídio, MACHADO, Ana Maria Netto. (Orgs). A bússola de escrever: sobre a função da orientação de teses e dissertações. 3 ed. São Paulo: Cortez, 2012.

TARDIF, M. Saberes docentes e formação profissional. Petrópolis: Vozes, 2002.

WARDE, Mirian Jorge. Sobre orientar pesquisa em tempos de pesquisa administrada. In: BIANCHETTI, Lucídio, MACHADO, Ana Maria Netto. (Orgs). A bússola de escrever: sobre a função da orientação de teses e dissertações. 3 ed. São Paulo: Cortez, 2012.

ZILBERMANN, Regina. Orientação: a aventura compartilhada. In: BIANCHETTI, Lucídio, MACHADO, Ana Maria Netto. (Orgs). A bússola de escrever: sobre a função da orientação de teses e dissertações. 3 ed. São Paulo: Cortez, 2012. 